\title{
Argument-Structure-Reducing Operations in Standard Arabic: An Exploratory Comparative Study
}

\author{
Abdellatif ED-DARRAJI ${ }^{1}$ \\ ${ }^{1}$ Faculty of Letters and Human Sciences, University of Ibn Tofail, Morocco \\ Correspondence: Abdellatif ED-DARRAJI, Faculty of Letters and Human Sciences, University of Ibn Tofail, \\ Kénitra, Morocco. E-mail: abdou.edd@aol.com
}

Received: January 28, 2018; Accepted: February 27, 2018; Published: March 8, 2018

\begin{abstract}
This paper attempts to examine some argument-structure-reducing operations in Standard Arabic (SA for short). It is proposed here that some affixes (viz. prefixes and infixes) can decrease the argument structure (or valence) of the subclass of change-of-state (COS for short) verbs in the language under study. More specifically, these affixes function as unaccusativizers or decausativizers in that they can derive unaccusative COS verbs from causative COS verbs by suppressing the external argument of the latter verbs and syntactically promoting the direct object to subject position. Crucially, the ability of these affixes to affect the argument structure and the morphosyntactic realization of arguments is not limited to SA, but it has been attested in some other languages, such as Italian, Russian, Chichewa, Spanish, French, Eastern Armenian, West Greenlandic, and Tzutujil, among others.
\end{abstract}

Keywords: Standard Arabic, argument structure, valence, change-of-state verbs, affixes, unaccusativizer

\section{Introduction}

This paper examines some argument-structure-reducing processes in Standard Arabic (SA for short), compared to other languages. (Note 1) It is thus proposed that some affixes (viz. prefixes and infixes) can alter the argument structure (or valence); i.e., the number of arguments a predicate takes, and argument realization of the subclass of causative COS verbs in the language under study. The main claim defended in this paper is that these affixes function as unaccusativizers or decausativizers in this language. Interestingly, the ability of these morphological entities to affect the argument structure of verbs is not limited to SA, but it has been attested in some other languages, such as Russian, Spanish, French, Italian, Eastern Armenian, West Greenlandic, Chichewa, and Tzutujil, among others.

This paper is structured as follows: section 1 discusses how unaccusative COS verbs (Note 2) are derived in SA. Section 2 briefly presents the theoretical background of the study. Section addresses the derivation of the subclass of unaccusative COS verbs in this language. Section 4 examines the interaction of affixes and COS verbs' argument structure in SA. Section 5 demonstrates how affixes can change the argument structure or valence of causative COS verbs in SA by decreasing it. Section 6 offers a brief comparison of SA with some other languages in terms of valence-decreasing morphology and its syntactic effects. Section 7 concludes the paper.

Before starting to discuss the behavioral patterns of unaccusative COS verbs in SA, the theoretical background of the present study is offered.

\section{Theoretical Background}

This study essentially hinges on the tenets of generative grammar, notably the Principles and Parameters Theory. The next section provides a brief overview of how these verbs are morphologically derived.

\section{Deriving Unaccusative COS Verbs in SA}

In this section, I address the issue raised in the introduction of how unaccusative COS verbs are derived in SA.

It should be emphasized here that unlike Hallman's (2006) proposal that causative verbs are derived from unaccusative verbs in Arabic by two morphological processes, namely 'ablaut' and 'gemination', claiming that the latter processes are valence increasing morphemes by considering them 'little- $v$ ', specifically $v_{\mathrm{AB}}$ and $v_{\mathrm{GEM}}$ respectively, inspired by Chomsky (1995), in what follows I will try to show, on the basis of empirical evidence, that in SA not all instances of causative verbs are derived from unaccusative verbs. I would claim that there is a 
subclass of unaccusative $\mathrm{COS}$ verbs in SA which is derived from causative COS verbs by adding some affixes and making a slight vocalic change.

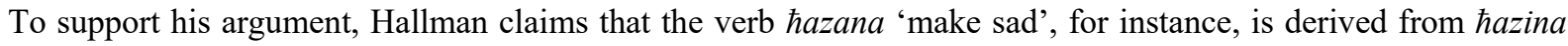
'be sad' by changing the second vowel /i/ into /a/. He adds that the verb hadama 'ruin' is, similarly, derived from the verb hadima 'fall to ruin,' and the verb harama 'prohibit' is derived from the verb haruma 'be prohibited'. Hallman also argues that the causative verb sammana 'fatten' is derived from the unaccusative verb samina 'be fat' by doubling the consonant $/ \mathrm{m} /$ and changing the vowel $/ \mathrm{i} /$ into /a/. For lack of space, I will not address Hallman's analysis in detail here.

\subsection{Verbs Beginning with the Prefix n-}

I would claim that in SA unaccusative COS verbs which begin with the prefix $n$ - are derived from causative COS verbs by the addition of this prefix at the beginning of the latter verbs. This claim can be illustrated by examples (1), (2), and (3) below.
(1) a. fataha
1-walad-u l-ba:b-a.
Opened-3MS the-boy-NOM the-door-ACC

'The boy opened the door.'

b. Pi-n-fataha

1-ba:b-u

PART-UNAC-opened.3MSG

$$
\text { the-door-NOM }
$$

'The door opened.'
(2)
a. kasara
1-PiৎSa:r-u
1-žisr-a.
broke.3MS the-tempest-NOM the-bridge-ACC
'The tempest broke down the bridge.'
b. Pi-n-kasara 1-žisr-u.
Unac- broke.3MS the-bridge-ACC
'The bridge broke.'
(3) a. qaTaYa 1-PiৎSa:r-u Pal-kahraba:?-a.
interrupted.3MS the-tempest-NOM the-electricity-ACC

'Electricity was interrupted by the tempest.'
b. Pi-n-qaTaSati
Pal-kahraba:?-u.
Unac-interrupted.3FS
the-electricity-NOM

'Electricity was interrupted.'

Obviously in (1b), the unaccusative COS verb Pinfataha 'was opened' is straightforwardly derived from the causative verb fataha 'open' in (1a) by the addition of the prefix $n$ - at the beginning of the verb and the removal of germination in the second.

Similarly, in (2b) the unaccusative COS verb Pinkasara 'broke' is derived from the causative verb kasara 'break' in (2a) by the addition of the prefix $n$ - at the beginning of the latter verb.

In (3b), the unaccusative COS verb PinqaTaSa-ti 'was interrupted' is equally derived from the causative COS verb qaTaSa 'interrupt' in (3a) by adding the prefix $n$ - at the beginning of the latter verb. The suffix $-t i$ attached to the verb PinqaTaSa in (3b) is a portmanteau morpheme encoding both gender and number.

On the basis of what has been said so far with regard to the derivation of unaccusative COS verbs beginning with the prefix $n$-, it can be concluded that all verbs belonging to the subclass of unaccusative COS verbs beginning with the prefix $n$-, such as verbs listed in table 1 below, are systematically derived by adding the prefix $n$ - at the beginning of the causative COS verbal stems from which they are derived. 
Table 1. List of unaccusative COS verbs beginning with the prefix n- in SA

\begin{tabular}{|c|c|c|c|c|}
\hline $\begin{array}{l}\text { Arabic derived } \\
\text { unaccusative COS } \\
\text { verb }\end{array}$ & $\begin{array}{l}\text { Approximate } \\
\text { meaning in English }\end{array}$ & $\begin{array}{l}\text { Arabic } \\
\text { causative } \\
\text { verb }\end{array}$ & COS & $\begin{array}{l}\text { Approximate } \\
\text { meaning in English }\end{array}$ \\
\hline Pinšaqqa & To split, crack & šaqqa & & To split, crack \\
\hline Pinqalaba & $\begin{array}{l}\text { To be turned, to be } \\
\text { turned over or upside } \\
\text { down, to be reversed }\end{array}$ & qalaba & & $\begin{array}{l}\text { To turn over or } \\
\text { upside down, to } \\
\text { reverse }\end{array}$ \\
\hline Pinkašafa & $\begin{array}{l}\text { To be unravelled, to be } \\
\text { uncovered }\end{array}$ & kašafa & & $\begin{array}{l}\text { To unravel, to } \\
\text { uncover }\end{array}$ \\
\hline PinqaSama & To be split & qaSama & & To split \\
\hline Pinqašara & To be skinned & qašara & & To skin \\
\hline Pinsalaxa & To be skinned & salaxa & & To skin \\
\hline Pinhadama & $\begin{array}{l}\text { To be demolished or } \\
\text { destroyed }\end{array}$ & hadama & & $\begin{array}{l}\text { To demolish, or } \\
\text { destroy }\end{array}$ \\
\hline Pinfakka & $\begin{array}{l}\text { To be untied or } \\
\text { unfastened, undone, } \\
\text { disconnected, detached }\end{array}$ & fakka & & $\begin{array}{l}\text { To untie or unfasten, } \\
\text { undo, disconnect, } \\
\text { detach }\end{array}$ \\
\hline Pinfalaqa & $\begin{array}{l}\text { To be split (apart), } \\
\text { crack; to burst, break } \\
\text { open }\end{array}$ & falaqa & & $\begin{array}{l}\text { To split (apart), } \\
\text { crack; to burst, } \\
\text { break open }\end{array}$ \\
\hline PinfaSala & $\begin{array}{l}\text { To be separated from, } \\
\text { to be disunited or } \\
\text { detached }\end{array}$ & faSala & & $\begin{array}{l}\text { To separate, to } \\
\text { disunite or detach }\end{array}$ \\
\hline PinTafa ?a & $\begin{array}{l}\text { To go out, be } \\
\text { extinguished }\end{array}$ & PaTafa Pa & & To extinguish \\
\hline Pinfataћa & To be opened & fataha & & To open \\
\hline Pinyalaqa & To be closed & yalaqa & & To close \\
\hline PintaSaša & To revive & Panৎaša & & To revive \\
\hline Pinkamaša & To shrink, to wrinkle & kamaša & & To shrink, wrinkle \\
\hline Pinba $\theta \theta a$ & To be scattered & $\mathrm{ba} \theta \theta \mathrm{a}$ & & To scatter \\
\hline Pinsadda & $\begin{array}{l}\text { To be closed; to be } \\
\text { obstructed }\end{array}$ & Sadda & & To close; to obstruct \\
\hline PinSahara & $\begin{array}{l}\text { To be fused, to be melt } \\
\text { down }\end{array}$ & Sahara & & To fuse, melt down \\
\hline Pinyasala & To be cleaned & yasala & & To clean \\
\hline PinhaDama & To be digested & haDama & & To digest \\
\hline Pinhašama & To be smashed & hašama & & To smash \\
\hline PinTamasa & $\begin{array}{l}\text { To be effaced; wiped } \\
\text { out }\end{array}$ & Tamasa & & To wipe out \\
\hline Pinmaћa: & $\begin{array}{l}\text { To be effaced; wiped } \\
\text { out }\end{array}$ & maha : & & To wipe out \\
\hline PinSazala & $\begin{array}{l}\text { To be separated, } \\
\text { secluded }\end{array}$ & Sazala & & To separate, seclude \\
\hline PinSakasa & To be reversed & Sakasa & & To reverse \\
\hline PinxalaSa & $\begin{array}{l}\text { To be dislocated, to be } \\
\text { disjoined, to be } \\
\text { disconnected }\end{array}$ & xalaSa & & $\begin{array}{ll}\text { To dislocate, to } \\
\text { disjoin, } & \text { to } \\
\text { disconnect } & \end{array}$ \\
\hline Pinxadaša & To be scratched & xadaša & & To scratch \\
\hline Pinhalla & $\begin{array}{l}\text { To be untied, } \\
\text { unfastened, loosened }\end{array}$ & halla & & $\begin{array}{l}\text { To untie, unfasten, } \\
\text { loosen }\end{array}$ \\
\hline
\end{tabular}

\subsection{Verbs Beginning with the Prefix ta-}

I also claim that unaccusative COS verbs which begin with the prefix $t a$ - in SA are derived by the addition of this prefix at the beginning of causative COS verbs. This claim is supported by the following pieces of data: 


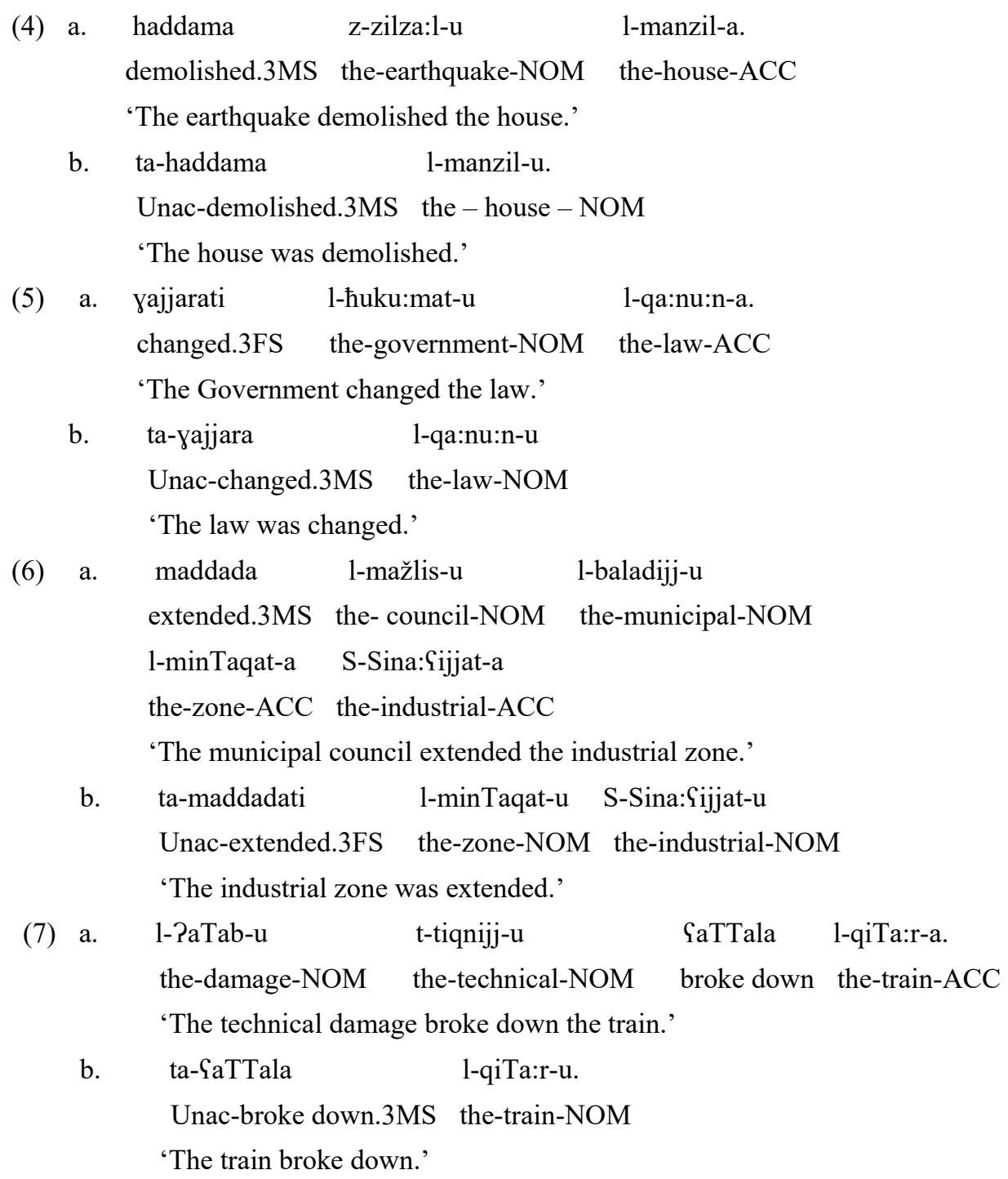

Notice that the prefix ta-is added at the beginning of the causative COS verb haddama 'demolish' in (4a) to derive the unaccusative COS verb tahaddama 'was demolished' in (4b).

Likewise, in (5b) the unaccusative COS verb taGajjara 'was changed' is derived by adding the prefix ta- at the beginning of the causative COS verb Gajjara 'change' in (5a).

In (6b), the unaccusative COS verb tamaddada-ti 'was extended' is equally derived by adding the prefix $t a$ - at the beginning of the causative COS verb maddada 'extend' in (6a). The suffix - $t i$ at the end of the verb tamaddadati is a portmanteau morpheme which marks both gender and number.

In (7b), the unaccusative COS verb taSaTTala 'broke down' is straightforwardly derived by adding the prefix taat the beginning of the causative COS verb SaTTala 'break down' in (7a).

Interestingly, and as has previously been noted with respect to the derivation of unaccusative COS verbs beginning with the prefix $n$-, it could be inferred from the examples given above that all verbs belonging to the subclass of unaccusative COS verbs beginning with the prefix $t a$-, such as verbs listed in table 2 below, are likely to be systematically derived by adding the prefix $t a$ - at the beginning of the causative COS verbs from which they are derived. 
Table 2. A list of unaccusative COS verbs beginning with the prefix ta- in SA

\begin{tabular}{|c|c|c|c|}
\hline $\begin{array}{lr}\text { Arabic } & \text { derived } \\
\text { unaccusative } \quad C O S \\
\text { verb }\end{array}$ & $\begin{array}{l}\text { Approximate meaning } \\
\text { in English }\end{array}$ & $\begin{array}{l}\text { Arabic causative COS } \\
\text { verb }\end{array}$ & $\begin{array}{l}\text { Approximate } \\
\text { meaning in English }\end{array}$ \\
\hline tamazzaqa & To be torn & mazzaqa & To tear \\
\hline tamaddana & To be civilized, urbanized & maddana & To civilize, to urbanize \\
\hline taћaDDara & To be civilized, urbanized & ћaDDara & To civilize, to urbanize \\
\hline taqallaSa & To be reduced & qallaSa & To reduce \\
\hline taqaššara & To be peeled, skinned & qaššara & To peel, to skin \\
\hline taqassama & To be divided & qassama & To divide \\
\hline tahassana & $\begin{array}{l}\text { To be improved, to } \\
\text { become better }\end{array}$ & hassana & $\begin{array}{l}\text { To improve, to make } \\
\text { better }\end{array}$ \\
\hline tahaššama & To be smashed & haššama & To smash \\
\hline tayajjara & To be changed, modified & yajjara & To change, to modify \\
\hline takawwana & To be formed & kawwana & To form \\
\hline tahaddama & $\begin{array}{l}\text { To be destroyed, to be } \\
\text { demolished }\end{array}$ & haddama & To destroy, to demolish \\
\hline tabaxxara & To evaporate & baxxara & To evaporate \\
\hline ta?ažžaža & To be heated & Pažžaža & To heat \\
\hline tabaY $\theta$ ara & To be scattered, dispersed & baS⿰ara & To scatter, to disperse \\
\hline tawallada & $\begin{array}{l}\text { To result or proceed from; } \\
\text { to be originated or } \\
\text { produced from }\end{array}$ & wallada & $\begin{array}{l}\text { To produce, to } \\
\text { generate, to create }\end{array}$ \\
\hline tafarraqa & To be separated & farraqa & To separate \\
\hline tašattata & $\begin{array}{l}\text { To dilate, expand, be } \\
\text { extended }\end{array}$ & šattata & $\begin{array}{l}\text { To dilate, to expand, to } \\
\text { extend }\end{array}$ \\
\hline tabaddada & $\begin{array}{l}\text { To be scattered; to be } \\
\text { dispersed, wasted }\end{array}$ & baddada & $\begin{array}{l}\text { To scatter; to disperse, } \\
\text { to waste }\end{array}$ \\
\hline tabaddala & To be changed, altered & baddala & To change, to alter \\
\hline taka:Oara & To be multiplied & 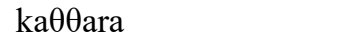 & To multiply \\
\hline ta?azzama & To come to a crisis & Pazzama & To bring to a crisis \\
\hline taћаTТаma & To be crashed & ћаTTama & To crash \\
\hline ta?a $\theta \theta$ ara & To be affected & 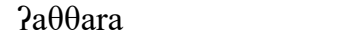 & To affect \\
\hline tažammada & To be frozen & žammada & To freeze \\
\hline tašaß̧aba & To be ramified & šaৎৎaba & To ramify \\
\hline talaTTafa & To become nice & laTTafa & To make nice \\
\hline tašarrada & $\begin{array}{l}\text { To wander, to be } \\
\text { homeless, to be displaced, } \\
\text { to be driven away, to be } \\
\text { expelled }\end{array}$ & šarrada & $\begin{array}{l}\text { To displace, to make } \\
\text { homeless, to drive } \\
\text { away, to expel }\end{array}$ \\
\hline takassara & To be broken to pieces & kassara & To break into pieces \\
\hline tadannasa & To be defiled & dannasa & To defile \\
\hline tawazzaৎa & To be distributed & wazzaৎa & To distribute \\
\hline taћarrara & To be liberated & harrara & To liberate \\
\hline ta-YaTTala & $\begin{array}{l}\text { Not to be working, to } \\
\text { have broken down }\end{array}$ & GaTTala & To break down \\
\hline tasammama & To be poisoned & sammama & To poison \\
\hline tafaћћama & To be carbonized & faћћama & To carbonize \\
\hline taba:Yada & $\begin{array}{l}\text { To be seperated or set } \\
\text { apart }\end{array}$ & ba:Yada & To separate or set apart \\
\hline tayarbala & To be sieved or sifted & yarbala & To sieve or sift \\
\hline tawassąa & $\begin{array}{l}\text { To be widened, to be } \\
\text { extended, expanded }\end{array}$ & wassa@a & $\begin{array}{l}\text { To widen, to extend, to } \\
\text { expand }\end{array}$ \\
\hline
\end{tabular}




\subsection{Verbs Containing the Infix -ta-}

A close scrutiny of the examples (8), (9), (10), and (11) below reveals that there are two derivational patterns of unaccusative COS verbs which contain the infix -ta-in SA: (i) the pattern of deriving this subclass of unaccusative COS verbs from triliteral causative COS verbal stems, and (ii) the pattern of deriving these verbs from quadriliteral causative COS verbal stems. The first subset is derived by the insertion of the infix -ta-after the first consonant and deleting the vowel following the first consonant of the triliteral verb, and adding the consonant $/ \mathrm{P} /$ and the vowel /i/ at the beginning of the verbal stem. The second subset is derived by the insertion of the infix -ta-after the second consonant of quadriliteral causative COS verbal stems and the replacement of the vowel /a/ after the first consonant / $/$ by the vowel /i/. So, it may be noted here that the derivation of the subsets of unaccusative COS verbs containing the infix -ta- is somewhat complex, and might cause some difficulty or confusion for learners of SA.

(8)

$$
\begin{array}{lll}
\text { 8) a. Pahraqa } & \text { 1-hari:q-u } & \text { 1-maSmal-a. } \\
\text { burned.3MS } & \text { the-fire-NOM } & \text { the-factory-ACC }
\end{array}
$$

'Fire burned the factory.'

b. Piћtaraqa 1-maSmal-u.

burned.Unac.3MS the-factory-NOM

'The factory was burned.'

(9) a. Pašৎala 1-PaTfa:1-u n-na:r-a fi: 1-ya:bat-i.

lit.3MPL the-boys-NOM the-fire-ACC in the-forest-OBL

'The boys lit the fire in the forest.'
b. PištaYalati n-na:r-u fi: 1-ya:bat-i.
lit.Unac.3FS the-fire-NOM in the-forest-OBL
'The fire was lit in the forest.'

(10)
a. xanaqa
1-ya:z-u
r-ražul-a.
suffocated.3MS the-gas-NOM the-man-ACC

'The gas suffocated the man.'

b. Pixtanaqa r-ražul-u.

suffocated.Unac.3MS the-man-NOM

'The man was suffocated.'

$\begin{array}{lllll}\text { (11) a. laћama } & \text { S-Sa:niৎ-u } & \text { Pažza:P-a } & \text { s-sajja:rat-i. } \\ & \text { welded.3MS } & \text { the-manufacturer-NOM } & \text { parts-ACC } & \text { the-car-GEN }\end{array}$

'The manufacturer welded the parts of the car.'

b. Piltaћamati Pažza:?-u s-sajja:rat-i.

welded.Unac.3MPL parts-NOM the-car-GEN

'The parts of the car were welded.'

As can clearly be noticed in ( $8 b)$, the infix -ta- is inserted between the second and the third consonants of the quadriliteral COS verb Paћraqa 'burn' in (8a) with the replacement of the vowel /a/ after the first consonant / $/$ by the vowel /i/, yielding the unaccusative COS verb Pittaraqa 'burned.'

The unaccusative COS verb PištaSalati 'was lit' in (9b) is equally derived by the insertion of the infix -ta- between the second and the third consonants of the quadriliteral COS verb ?ašৎala 'light' in (9a) with the replacement of the vowel /a/ after the first consonant / $/$ by the vowel /i/.

Notice that in (10b), the unaccusative COS verb Pixtanaqa 'was suffocated' is similarly derived by the insertion of the infix -ta-after the first consonant of the verbal stem and deleting the vowel following the latter consonant of the triliteral verb xanaqa 'suffocate' in (10a), and adding the consonant $/ \mathrm{P} /$ and the vowel $/ \mathrm{i} /$ at the beginning of the verbal stem.

Just as in (10b), the unaccusative COS verb Piltahamati 'were welded' in (11b) is derived by the insertion of the infix -ta- between the first consonant of the triliteral verb latama 'weld' in (11a), and adding the consonant /?/ 
and the vowel $/ \mathrm{i} /$ at the beginning of the verbal stem. Tables 3 and 4 below show some other unaccusative COS verbs containing the infix - $t a$ - in SA.

Table 3. A list of unaccusative COS verbs containing the infix -ta- derived from triliteral verbal stems in SA

\begin{tabular}{|c|c|c|c|}
\hline $\begin{array}{l}\text { Arabic } \quad \text { derived } \\
\text { unaccusative COS verb }\end{array}$ & $\begin{array}{l}\text { Approximate meaning } \\
\text { in English }\end{array}$ & $\begin{array}{ll}\text { Arabic } & \text { causative } \\
\text { COS verb } & \\
\end{array}$ & $\begin{array}{l}\text { Approximate } \\
\text { meaning in English }\end{array}$ \\
\hline Pixtanaqa & To be choked, suffocated & xanaqa & To choke, suffocate \\
\hline Piltahama & $\begin{array}{l}\text { To be stuck together, to } \\
\text { be welded, to be united }\end{array}$ & laћama & $\begin{array}{l}\text { To stick together, to } \\
\text { weld, to unite }\end{array}$ \\
\hline Pilta Pama & To be welded & la?ama & $\begin{array}{l}\text { To weld, to put } \\
\text { together }\end{array}$ \\
\hline Piktawa : & $\begin{array}{l}\text { To be cauterized ; to be } \\
\text { burned }\end{array}$ & kawa: & To cauterize ; to burn \\
\hline Pirtawa & To quench one's thirst & rawa: & $\begin{array}{l}\text { To quench someone's } \\
\text { thirst }\end{array}$ \\
\hline Pimtala?a & To become full & malaPa & To make full \\
\hline Pistawa : & To become even, flat & sawwa: & To make even, flat \\
\hline Piltawa: & To be twisted, to be bent & lawa: & To twist, to bend \\
\hline PixtalaTa & To be mixed & xalaTa & To mix \\
\hline
\end{tabular}

Table 4. A list of unaccusative COS verbs containing the infix -ta-derived from quadriliteral verbal stems in SA

\begin{tabular}{|c|c|c|c|}
\hline $\begin{array}{ll}\text { Arabic } & \text { derived } \\
\text { unaccusative COS verb }\end{array}$ & $\begin{array}{l}\text { Approximate meaning } \\
\text { in English }\end{array}$ & $\begin{array}{l}\text { Arabic causative } \\
\text { COS verb }\end{array}$ & $\begin{array}{l}\text { Approximate } \\
\text { meaning in English }\end{array}$ \\
\hline Piћtaraqa & To be burned & Paћraqa & To burn \\
\hline PištaSala & To be flamed & PšSala & To burn, to light \\
\hline Piltahaba & $\begin{array}{l}\text { To be flamed, to be } \\
\text { blazed }\end{array}$ & Plhaba & To flame, blaze \\
\hline Pixtalla & $\begin{array}{l}\text { To be disturbed, } \\
\text { disordered, deranged, } \\
\text { upset, unbalanced }\end{array}$ & Paxalla & $\begin{array}{l}\text { To disturb, to } \\
\text { disorder, to upset, to } \\
\text { unbalance }\end{array}$ \\
\hline PiltaSaqa & To be stuck & PalSaqa & To stick \\
\hline Piytana & To become rich & Payna: & To make rich \\
\hline Piftaqara & To become poor & Pafqara & To make poor \\
\hline
\end{tabular}

It follows from the above discussion that I have identified three derivational patterns yielding three categories of unaccusative COS verbs in SA: (i) the subclass of verbs formed by the addition of the prefix $n$ - at the beginning of the causative COS verbal stem, (ii) the category of verbs formed by the addition of the prefix $t a$ - at the beginning of the causative COS verbal stem, and (iii) the subset of verbs formed by the insertion of the infix -ta- in the causative COS verbal stem accompanied by a vocalic change.

\subsection{Some Counterevidence}

As mentioned in the introduction of this paper, an important point that should be clear at this juncture is that not all SA unaccusative COS verbs are derived from causative COS verbs. In other words, there is a subset of unaccusative COS verbs which does not alternate with causative COS verbs. Indeed, it has been noticed that some verbs which mysteriously resemble derived unaccusative COS verbs in their forms, but which are lexicalized as such. These verbs can be exemplified by the following: PinqaraDa 'become extinct,' Pindaeara 'perish,' Pindala $a$ 'break out,' ta?a:kala 'lose some parts' or 'corrode,' and taDa:?ala 'become smaller.'

I would claim here that unaccusative COS verbs which are derived from causative COS verbs in SA may be characterized as core unaccusative COS verbs; whereas unaccusative COS verbs which are not derived from causative COS verbs may be described as peripheral or lexicalized unaccusative COS verbs.

It should be capitalized here that these allegedly underived or lexicalized unaccusative COS verbs need more research and deeper analysis to unravel and account for their characteristic properties and behavior in their crosslinguistic dimension. 
Having provided a brief overview of the derivation of some unaccusative COS verbs in SA, I now turn to address the interaction of some affixes with the argument structure and argument realization of some COS verbs in the language under study.

\section{Affixes and COS Verbs' Argument Structure in SA}

In this section, I will try to address the issue raised in the introduction of whether affixes can affect the argument structure and argument realization of COS verbs in SA.

A crucial point worth making at this juncture is that SA is a Semitic language which has rich and complex morphology. In other words, it has a variety of affixes, be they inflectional or derivational, which have crucial semantic and syntactic repercussions, among others. For present purposes, I focus the discussion here on the morphosyntactic effects of the derivational prefixes $n$ - and $t a$ - and the derivational infix -ta-

Concretely, I hereafter address the issue of how the previous affixes interact with and affect the argument structure and argument realization of the subclass of causative COS verbs in SA.

\subsection{Causative COS Verbs' Argument Structure and Argument Realization in SA}

As is well-known in the relevant literature, causative COS verbs tend to be associated with two arguments crosslinguistically: An internal argument bearing the Patient/Theme theta role and an external one bearing the Agent theta role. In English, for instance, we find verbs such as: break, melt, crack, freeze, evaporate, etc. In French, we find verbs like casser 'break,' fondre 'melt,' liquéfier 'liquefy,' congeler 'freeze,' exploser 'explode,' démolir 'demolish,' fragmenter 'split up,' etc.

Interestingly, SA constitutes no exception as far as causative COS verbs are concerned. For expository clarity and convenience, a characteristic property of these verbs is that they tend to select two arguments, viz. an internal argument and an external one. The internal argument bears the Patient/Theme theta role (i.e., the entity undergoing the action denoted by the verbal predicate) and the external one bears the Agent theta role (i.e., the actor or doer of the action that brings about the change in the state of the internal argument). Consider the following examples which illustrate what has just been noted:

$$
\begin{array}{lll}
\text { Pahraqa } & \text { 1-hari:q-u } & \text { 1-maSmal-a } \\
\text { burned.3MS } & \text { the-fire-NOM } & \text { the-factory-ACC }
\end{array}
$$

'Fire burned the factory.'

\begin{tabular}{|c|c|c|}
\hline $\begin{array}{l}\text { yajjarati } \\
\text { changed.3FS }\end{array}$ & $\begin{array}{l}\text { 1-huku:mat-u } \\
\text { the-government-NOM }\end{array}$ & $\begin{array}{l}\text { l-qa:nu:n-a } \\
\text { the-law-ACC }\end{array}$ \\
\hline \multicolumn{3}{|c|}{ 'The Government changed the law.' } \\
\hline xanaqa & 1-уа:z-u & r-ražul-a \\
\hline Iffocated.3MS & the-gas-NOM & the-man-ACC \\
\hline
\end{tabular}

At first glance, we clearly notice that in (12) the causative COS verb ?aћraqa 'burn' selects two arguments, namely an internal argument l-maSmal-a 'the factory' and an external one $l$ - $\hbar a r i: q-u$ 'the fire'. The internal argument thus bears the Patient theta role (i.e., it is undoubtedly the undergoer of the action of burning denoted by the verbal predicate) and the external one bears the Agent theta role (i.e., it is the actor or doer of the action of burning that brings about the change in the state of the internal argument, viz. the burned factory).

In (13), the causative COS verb rajjara 'change' equally selects two arguments, namely an internal argument $l$ qa:nu:n-a 'the law' and an external one l-huku:mat-u 'the government.' The internal argument obviously bears the Theme theta role (i.e., it is the entity undergoing the action of changing denoted by the verbal predicate) and the external one bears the Agent theta role (i.e., it is the actor or doer of the action of changing that brings about the change in the state of the internal argument, namely the changed law).

The same pattern is noticed in (14) where the causative COS verb xanaqa 'suffocate' is associated with two arguments, namely an internal argument $r$-ražul- $a$ 'the man' and an external one $l$-ya:z- $u$ 'the gas.' The internal argument obviously bears the Patient theta role (i.e., it is the undergoer of the action of suffocating denoted by the verbal predicate) and the external one bears the Agent theta role (i.e., it is the actor or doer of the action of suffocating that causes the change in the state of the internal argument, namely the suffocated man). 
Viewed from a syntactic perspective, the internal arguments in (12), (13), and (14), viz. l-maSmal-a, l-qa:nu:n-a, and $r$-ražul- $a$ are projected as direct objects in the respective constructions in which they appear. In contrast, the

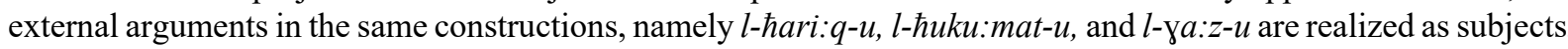

Having examined the argument structure and argument realization of some causative COS verbs in SA, I now turn to examine the argument structure and argument realization of some unaccusative COS verbs in the language being studied.

\subsection{Unaccusative COS Verbs' Argument Structure and Argument Realization in SA}

As is well established cross-linguistically, the subclass of unaccusative verbs uniformly selects one argument, specifically an internal argument and lacks an external argument. On the basis of evidence culled from SA, I assume that unaccusative COS verbs in SA constitute no exception. This subclass of verbs, more specifically those which are derived from causative COS verbs, tends to be associated with one and only one internal argument.

For the sake of expository clarity and concreteness, consider the following illustrative examples:

?i-n-fataha

1-ba:b-u

PART-Unac-opened.3MSG

the-door-NOM

'The door opened.'

$\begin{array}{ll}\text { Pi-n-kasara } & \text { 1-žisr-u } \\ \text { PART-Unac- broke.3MS } & \text { the-bridge-ACC }\end{array}$

'The bridge broke.'

$$
\text { Pi-n-qaTaYati Pal-kahraba:?-u }
$$

PART-Unac-interrupted.3FS the-electricity-NOM

'Electricity was interrupted.

$$
\begin{array}{ll}
\text { ta-haddama } & \text { 1-manzil-u. } \\
\text { Unac -was demolished-3MS } & \text { the - house-NOM }
\end{array}
$$

'The house was demolished.'

$$
\begin{array}{ll}
\text { ta-yajjara } & \text { l-qa:nu:n-u } \\
\text { Unac-changed.3MS } & \text { the-law-NOM }
\end{array}
$$

'The law was changed.'

$$
\begin{array}{lll}
\text { ta-maddadati } & \text { 1-minTaqat-u } & \text { S-Sina:Sijjat-u } \\
\text { Unac - was extended.3FS } & \text { the-zone-NOM } & \text { the-industrial-NOM }
\end{array}
$$

'The industrial zone was extended.'

$$
\begin{array}{ll}
\text { ta-YaTTala } & \multicolumn{1}{c}{\text { l-qiTa:r-u }} \\
\text { Unac-broke down.3MS } & \text { the-train-NOM } \\
\text { 'The train broke down.' } & \\
\text { Piћtaraqa } & \text { 1-maSmal-u } \\
\text { burned.Unac.3MS } & \text { the- factory-NOM }
\end{array}
$$

'The factory was burned.'

$$
\begin{array}{lll}
\text { PištaGalati } & \text { n-na:r-u } & \text { fi: l-ya:bat-i } \\
\text { was lit.Unac.3FS } & \text { the-fire-NOM } & \text { in the-forest-OBL }
\end{array}
$$

'The fire was lit in the forest.'

$\begin{array}{lll}\text { Piltaћamati } & \text { Pažza:P-u } & \text { s-sajja:rat-i } \\ \text { were welded.Unac.3MPL } & \text { parts-NOM } & \text { the-car-GEN }\end{array}$

'The parts of the car were welded.'

Notice that in (15), the unaccusative COS verb Pinfataha 'was opened' selects one argument, namely the internal argument $l-b a: b-u$ 'the restaurant.' This internal argument obviously bears the Theme theta role (i.e., it is the undergoer of the action of opening denoted by the verbal predicate). 
In (16), one internal argument is selected by the unaccusative COS verb Pinkasara 'broke', namely $l$-žisr- $u$ 'the bridge.' This internal argument bears the Patient theta role (i.e., it is the undergoer of the action of breaking denoted by the verbal predicate).

Similarly, the unaccusative COS verb PinqaTaSa 'was interrupted' in (17) selects Pal-kahraba:?-u 'the electricity' as its unique internal argument which bears the Patient theta role.

In examples (18) through (24), the unaccusative COS verbs ta-haddama, ta-yajjara, ta-maddada, ta-\{aTTala, Piћtaraqa, PištaGala, and Piltaћama uniformly take one and only one internal argument, respectively l-manzil-u, $l$ qa:nu:n-u, l-minTaqat-u, l-qiTa:r-u, l-maSmal-u, n-na:r-u, Pažza:?-u.

Concretely, in the examples given above (viz. from (15) to (24)), the internal arguments l-maTSam, l-žisr, Palkahraba:P, l-manzil, l-qa:nu:n, l-minTaqat, l-qiTa:r, l-maSmal, n-na:r, and Pažza:? originate in the object position at D-structure (i.e., the position normally occupied by objects of transitive verbs) where they are assigned the relevant theta role.

Essentially adopting Travis's (2010) and Nossalik's (2010) phrase structure model, and as far as the syntactic projection of unaccusative COS verbs' argument structure is concerned, it might be proposed here that the internal arguments in the examples above are likely to move from their D-Structure position within VP to the Spec(ifier) position of InAspP (Inner Aspect Phrase) directly above VP, and end up in [Spec, TP] (i.e., in the Specifier position of Tense Phrase), where they are promoted to subject position of the clause and are, consequently, likely to fulfil Agreement requirements and be assigned Nominative Case, as illustrated by the structures (25), (26), and (27) below.

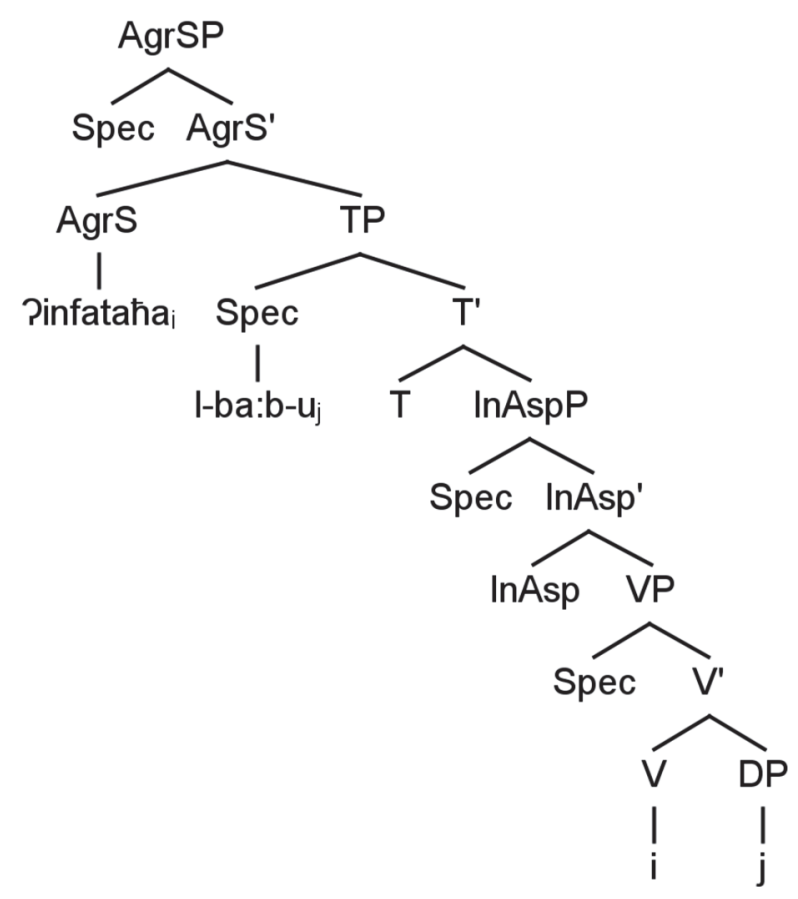

It might be proposed that in (25) the causative COS verb stem fataћa 'open' is generated under the V node at DStructure; it first adjoins to the InAsp node under which the unaccusativizer head $n$-is generated, then the resulting verbal complex moves on to the $\mathrm{T}$ node and ends up under the AgrS node, to fulfil Case and agreement requirements, as a full-fledged unaccusative COS verb Pi-n-fataha 'was opened.'

As far as the DP $l-b a: b$ 'the restaurant' in the above tree diagram is concerned, it might be proposed that it is generated in the direct object position within VP at D-Structure where it is assigned the Theme theta-role. It moves cyclically to [Spec, InAspP], then to [Spec, TP] where it surfaces as $l-b a: b-u$ assigned Nominative case and, consequently, becoming the subject of the sentence in satisfaction of the Extended Projection Principle (EPP for short), which roughly stipulates that sentences need subjects. 
(26)

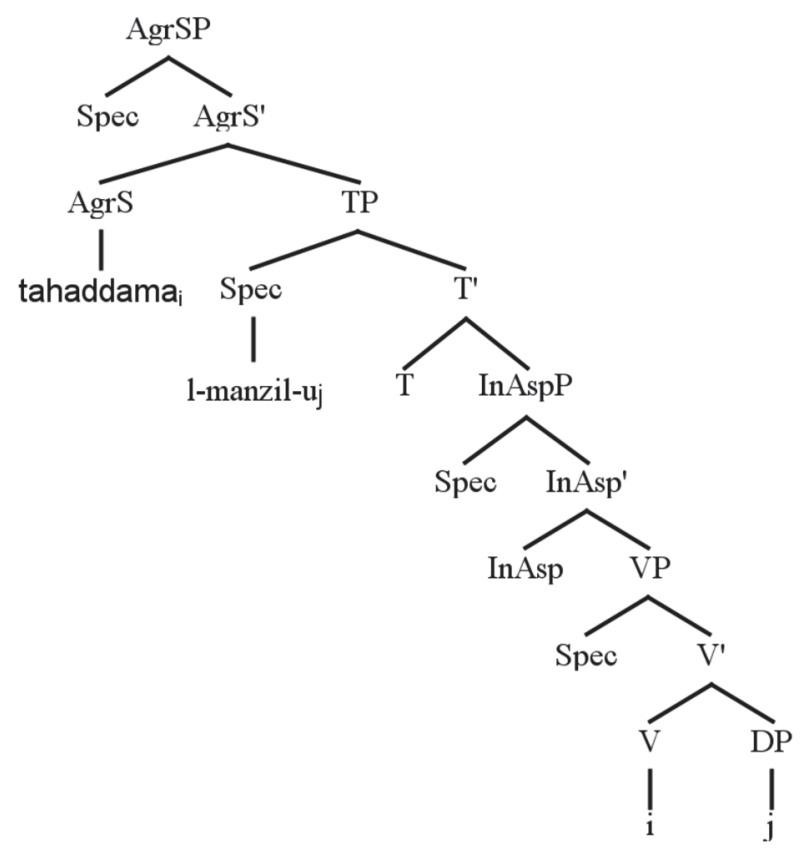

As we have seen in (25), it might equally be proposed that in (26) the causative COS verb stem haddama 'demolish' is generated under the $\mathrm{V}$ node at $\mathrm{D}$-Structure, it first adjoins to the InAsp node under which the unaccusativizer head $t a$ - is generated, then the resulting verbal form moves up to the T node and ends up under the AgrS node, to fulfil Case and agreement requirements, as a full-fledged unaccusative COS verb tahaddama 'was demolished.'

Concerning the DP l-manzil 'the house' in the above tree diagram, it might be proposed that it occupies the direct object position within VP at D-Structure where it is assigned the Patient theta-role, and it moves cyclically to [Spec, InAspP], then to [Spec, TP] where it surfaces as l-manzil-u assigned Nominative Case, and becoming the subject of the sentence, in fulfilment of the EPP.

(27)

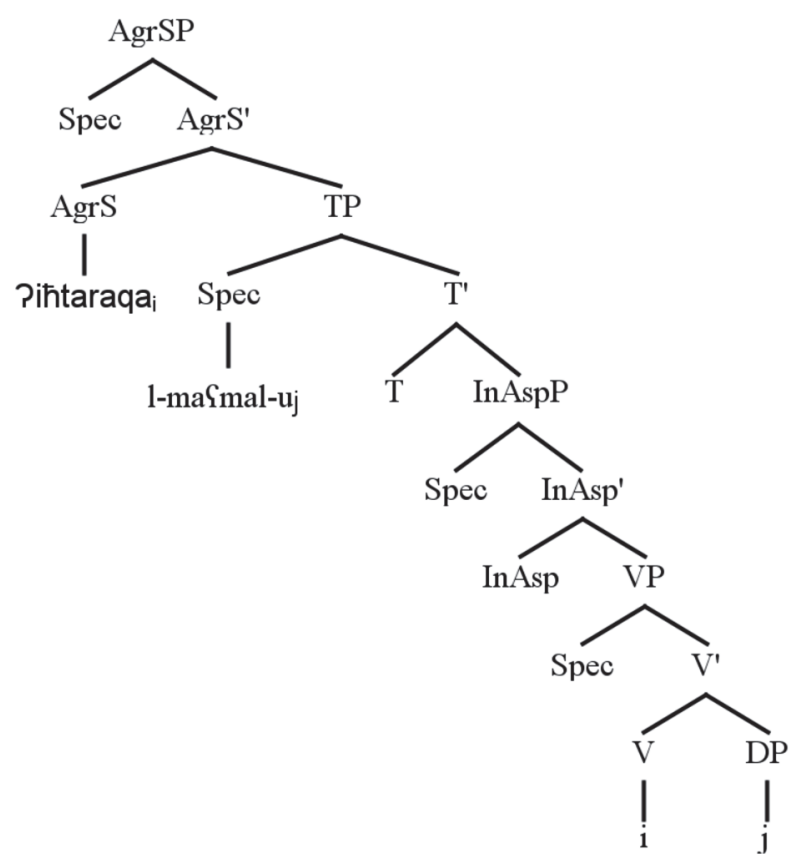

It might equally be claimed that in (27) the causative COS verb stem Patraqa 'burn' is generated under the V node at D-Structure, it first adjoins to the InAsp node under which the unaccusativizer head - $t a$ - is generated, then the 
resulting verbal form moves up to the $\mathrm{T}$ node and ends up under the AgrS node, to fulfil Case and agreement requirements, as a full-fledged unaccusative COS verb Pihtaraqa 'was burned.'

As far as the DP l-maSmal 'the factory' in the above tree diagram is concerned, it might be proposed that it occupies the direct object position within VP at D-Structure where it is assigned the Patient theta-role, and it moves cyclically to [Spec, InAspP], then to [Spec, TP] where it surfaces as the subject l-maSmal-u of the sentence, as is required by the EPP, and is consequently assigned Nominative case.

\section{Argument Structure or Valence-Decreasing Affixes in SA}

As is well established in the literature, the way(s) in which the argument structure of a verbal predicate is syntactically realized may be affected by certain identified and attested operations or processes, among them the following have been examined and tested in a number of languages: (i) passivization, (ii) middle formation, (iii) reflexivization, (iv) the causative-inchoative alternation, (v) applicative, and (vi) antipassive. (Note 3)

Other processes have also been identified in the literature which can alter the argument structure of verbal predicates, among these processes figure out some morphological operations such as word formation. (Note 4) For present purposes, I will discuss two processes subsumed under word formation, namely prefixation and infixation in SA, which I claim to be argument-reducing operations.

\subsection{The Process of Prefixation}

\subsubsection{The prefix $n$ -}

As has been noted above, the prefix $n$ - plays a crucial role in deriving a subset of unaccusative COS verbs in SA. What interests us more here is not the derivational role of this bound morpheme, but rather its ability to affect the argument structure or valence of causative COS verbs to which it is attached. I hence claim that this affix is morphosyntactically active.

Concretely, when this prefix is added at the beginning of a causative COS verb, it tends to systematically alter its argument structure by decreasing it by one. The external argument is consequently suppressed from the construction and the internal argument which bears the Patient theta role is promoted to subject.

One clear-cut result of this morphosyntactic process is that the causative verb is straightforwardly unaccusativized, yielding an unaccusative COS verb with one-place argument structure.

It should also be noted here that this affix is productive in SA, to the extent that it can derive a significant number of unaccusative COS verbs. I have listed some 25 verbs, as is illustrated in table 1.

\subsubsection{The prefix ta-}

Another prefix which equally plays a significant role in deriving unaccusative COS verbs in SA is the prefix ta-. As has already been claimed above, when this bound morpheme is added at the beginning of some causative COS verbs it tends to change their argument structure or valence by reducing it by one. The external argument is consequently erased from the construction and the internal argument which bears the Patient theta role is promoted to subject. The straightforward and obvious result of this morphosyntactic process, then, is that the causative verb is unaccusativized or decausativized, yielding an unaccusative COS verb with one-place argument structure.

Like the prefix $n$ - examined above, the prefix ta- is therefore very active in SA morphosyntactically speaking. Concretely, it allows the derivation of an important number of unaccusative verbs from causative COS verb stems.

Furthermore, this affix is highly productive in SA. This is corroborated by the evidence listed in table 2. Not less than 37 verbs have been listed.

\subsection{The Process of Infixation}

The infix -ta-

As has already been put forward, the infix -ta-plays a not insignificant role in deriving some unaccusative COS verbs in SA. Concretely, when this infix is inserted or incorporated in some causative COS verbal stems, it changes their argument structure or valence by reducing it by one. The external argument is consequently cut off from the construction and the internal argument which bears the Patient theta role is promoted to subject. As a result of this morphosyntactic process, the causative COS verb is unaccusativized, yielding an unaccusative COS verb with oneplace argument structure.

From what has been said above, it clearly follows that the infix - $t a$ - is also active in SA. However, its productivity is somewhat limited, as far as I know. I have listed some 15 verbs, as tables 3 and 4 show. 


\section{A Brief Comparison of SA with Some Other Languages in Terms of Valence-Decreasing Morphology and Its Syntactic Effects}

Having discussed and demonstrated how some morphological processes (prefixation and infixation) may change the argument structure or valence of causative COS verbs in SA, it seems somewhat relevant to undertake a brief comparison between SA and some other languages for typological reasons.

To begin with, Ramchand (2013) cites Haspelmath who points out that there are languages where decausativizing/reflexive morphology is added to a transitive/causative form to give an intransitive (e.g., si in Italian, se in French, sja in Russian) (p.12).

According to Ramchand, in Italian, the intransitive version of the verb in causative alternation shows up obligatorily with the marker $s i$ (which elsewhere functions as a reflexive clitic pronoun).

a. Il vento ha rotto la finestra.

the wind has broken the window

'The wind broke the window.'

b. La finestra $*($ si) è rotta.

the window REFL is broken

'The window broke.'

(Ramchand 2013: 17)

Similarly, in Spanish the reflexive morpheme se is required in the inchoative form of the causative/inchoative alternation. Without se, the inchoative form is ungrammatical. This is supported by the following examples:
a. Los vasos se rompieron.
the glasses REFL broke
'The glasses broke.'
b. *Los vasos rompieron.
'The glasses broke.'
(Whong-Barr 2005:269)

Furthermore, Haspelmath and Sims (2010:238) offer the following example of a valence-decreasing operation in Russian, namely suffixation:
a. Vera zakryla dver'.
Vera.NOM closed door.ACC
'Vera closed the door.'
b. Dver' zakryla.s'.
door.NOM closed-ANTIC
'The door closed.'

In (30b), we can clearly observe that the Agent 'Vera' is removed from the argument structure by the addition of the anticausative suffix $-s$ ' to the verb zakryla. In this example the Patient $d v e r$ 'door' becomes the subject of the sentence.

Interestingly, SA differs from Russian in the morphological entity involved in altering the argument structure of a causative verb. Consider the following example:
(31)
a. yalaqa
Abdeljouad-u
1-ba:b-a
closed.3MS Abdeljouad-NOM
the-door-ACC

'Abdeljouad closed the door.'
b. Pi-n-yalaqa
1-ba:b-u
PART-Unac.closed.3MS the-door-NOM
'The door closed.' 
Notice that in (31b), the subject Abdeljouad is removed from the argument structure of the verb ralaqa 'close' by the addition of the prefix $n$-. It follows, then, that unlike in Russian, where the suffix $-s$ ' alters the argument structure of the causative verb, in SA it is the prefix $n$ - which changes the argument structure. One could say, then, that this linguistic phenomenon is a clear example of linguistic variation. In line with this observation, Wunderlich (2012) notes: [M] ost operations on argument structure can be marked morphosyntactically (by derivational affixes or syntactic constructions), or be left unmarked and only visible by their effects in the morphosyntactic complement structure. Languages widely differ in the amount of marking, and, of course, in the specific means of realizing these operations. (p.2230)

Haspelmath and Sims (2010:239) give another example of an argument structure changing operation in Chichewa, viz. the resultative (or stative) operation, illustrated by the construction in (32) below.

$$
\begin{aligned}
& \text { Chitseko chi-na-tsek-eka. } \\
& \text { door } \quad \text { 3SG-PST-close-RESULT } \\
& \text { 'The door was closed (= in a closed state).' }
\end{aligned}
$$

No oblique agent is allowed in (32). This is illustrated by the ungrammatical construction in (33) below.

$$
\begin{aligned}
& \text { *Chitseko chinatsekeka ndi Naphiri. } \\
& \text { 'The door was in a closed state by Naphiri.' }
\end{aligned}
$$

Haspelmath and Sims provide another valence-changing operation which is the 'antipassive.' (Note 5) They cite an example of an active and an antipassive construction from West Greenlandic as follows:

$\begin{array}{rlrl}\text { (34) a. } & \text { Qimmi-p } & \text { inu-it } & \text { tuqup-pai. } \\ & \text { dog-ERG.SG person-ABS.PL } & \text { kill-3SG.SBJ/3PL.OBJ.IND } \\ & \text { 'The dog killed the people.' } & \text { (Active) } \\ \text { b. } & \text { Qimmiq (inun-nik) } & \text { tuqut-si-vuq. } \\ & \operatorname{dog} \text { (ABS) } & \text { person-INST.PL } & \text { kill-ANTIP-3SG.IND } \\ & \text { 'The dog killed (people).' } & \text { (Antipassive) } \\ & \text { (Fortescue 1984:86, 206) } & \end{array}$

As can be clearly noticed in (34b), the antipassive morpheme -si- renders the object inun-nik optional, i.e., the argument structure of the verb tuqut 'kill' is affected by the addition of this affix.

Furthermore, Haspelmath and Sims (2010:240) point out that some languages have a valence-changing operation called 'deobjective' in which an affix does not allow the patient to be expressed. They cite the following example from Tzutujil:

$$
\begin{aligned}
& \text { a. } \quad \text { x-Ø-uu-ch'ey } \\
& \text { PST-3SG.OBJ-3SG.SBJ-hit } \\
& \text { 'He hit him.' } \\
& \text { b. x-Ø-ch'ey-oon-i } \\
& \text { PST-3SG.SBJ-hit-DEOBJ-PST } \\
& \text { 'He was hitting.' } \\
& \text { (Dayley 1985:89, 116) }
\end{aligned}
$$

As can clearly be noticed in (35b), the suffix $-i$ does not allow a patient to be expressed.

In view of the previous discussion and analysis, it may be concluded that the ability of certain morphological items (most notably affixes) to reduce or decrease the argument structure or valence of some verbal predicates is not limited to Standard Arabic, but it has equally been attested cross-linguistically, though there are differences and similarities between these languages with respect to the type of affixes involved (be they prefixes, infixes or suffixes), to the extent that some languages make use of prefixes to change the valence of certain verbs, others employ suffixes to alter the argument structure of verbs, and, as has previously been demonstrated, in other languages infixes may serve as valence-changing devices.

Interestingly, it follows from the discussion in this section that a common characteristic of Italian, Spanish, Russian, Chichewa, West Greenlandic, Tzutujil, and SA is that all of these languages add some morphological entities to 
constructions to alter the argument structure of certain verbs by reducing it. This observation may have some implications for Universal Grammar and may be worth investigating.

This conclusion might lead one to raise the issue of the universality of valence-decreasing operations and mechanisms and its possible implications for linguistic typology, in correlation with what Babby (2009) insightfully puts forward:

Languages typically have a closed class of productive, diathesis-altering, paradigm-creating affixes (-af), which have their own diathesis. Since these affixes both alter V's initial diathesis and head their own projections in the syntax (afP), diathesis theory provides a natural setting in which an important lexalist dictum can be formalized: in addition to parameter-setting, the morphosyntactic differences we observe among languages can in large part be attributed to the language-specific properties of their diathesis-bearing affixes. (p.13)

\section{Conclusion}

To sum up, it has been argued in this paper that unlike Hallman's (2006) account which claims that causative verbs are derived from unaccusative verbs in Arabic by the processes on ablaut and gemination, it has been argued that there still is a subclass of unaccusative COS verbs in SA which is systematically derived from causative COS verbs by the addition of some affixes, be they prefixes such as $n$ - and $t a$ - or infixes such as -ta-. When these affixes are attached to or inserted in causative COS verbal stems, unaccusative COS verbs are straightforwardly and systematically derived yielding three verbal paradigms or patterns depending on the type of the affix (namely, the prefixes $n$ - and $t a$-, and the infix -ta-), the subject is consequently removed from the syntactic structure, and the direct object is promoted to subject position.

Importantly, I have shown that some verbal affixes (more specifically the prefixes $n$ - and $t a$ - and the infix -ta-) tend to mark the subclass of unaccusative COS verbs in SA.

As has equally been examined and illustrated earlier in this paper, unaccusative COS verbs tend to show the same argument realization patterns in SA. In other words, the Patient/Theme or undergoer of the action is systematically realized in the syntactic structure as a subject, which is generally assumed to occupy the object position at the level of D-Structure.

Of equal importance, it has been found out that the above mentioned affixes function as unaccusativizers or decausativizers in this language. These affixes are also able to alter the argument structure or valence of a subset of causative COS verbs by decreasing it by one.

Another important finding is that morphology cross-linguistically interacts with syntax, so much so that some morphemes (most notably affixes, be they prefixes, infixes or suffixes) can change the argument structure or valence of certain verbs by decreasing or reducing it. This is corroborated with evidence culled from different languages. This promising and interesting linguistic phenomenon deserves deeper and cross-linguistic analysis and investigation to account for the variation in the types of morphemes which have syntactic effects or consequences (most notably argument structure or valence-changing effects) and to reveal the possible implications for what is called 'Universal Grammar' and 'parameterization.' It seems fairly reasonable to assert that addressing this issue is beyond the scope of the present study.

\section{References}

Al-Ghalayini, M. (2010). ža:miৎ d-duru:s Pal Sarabija (The Compilation of Arabic Lessons). Beirut: Resala Publishers.

Babby, L. H. (2009). The Syntax of Argument Structure. Cambridge: Cambridge University Press.

Carnie, A., Sato, Y., \& Siddiqi, D. (2014). The Routledge Handbook of Syntax. New York: Routledge.

Chomsky, N. (1995). The minimalist program. Massachussetts: MIT.

Hallman, P. (2006). "Causativity and transitivity in Arabic.” Ms. MIT.

Haspelmath, M., \& Sims, A.D. (2010). Understanding Morphology. (2nd ed.). London: Hodder Education. ISBN: 9780340950012.

Kiss, T., \& Alexiadou, A. (2015). Syntax - Theory and Analysis 1. Berlin: De Gruyter Mouton.

Mckoon, G., \& Macfarland, T. (2000). Externally and Internally Caused Change of State Verbs. Language, 76(4), 833-858. https://doi.org/10.2307/417201

Nossalik, L. (2010). What exactly does Outer Aspect encode? Proceedings of the 2010 Annual Conference of the Canadian Linguistic Association. Retrieved July 10th, 2014, from http://homes.chass.utoronto.ca/ cla- 
ac1/actes2010/CLA2010_Nossalik.pdf

Payne, T. (1997). Describing Morphosyntax: A Guide for Field Linguists. Cambridge: Cambridge University Press.

Ramchand, G. C. (2013). Argument structure and argument structure alternations. The Cambridge Handbook of Generative Syntax. Cambridge: Cambridge University Press.

Reinhart, T., \& Siloni, T. (2005). The lexicon-syntax parameter: Reflexivization and other arity operations. Linguistic Inquiry, 36(3), 89-436. https://doi.org/10.2307/4179330

Travis, L. (2010). Inner aspect: The articulation of VP. Studies in Natural Language and Linguistic Theory, 80. London: Springer Science+Business Media.

Whong-Barr, M. (2005). Transfer of argument structure and morphology. Proceedings of the $7^{\text {th }}$ Generative Approaches to Second Language Acquisition Conference, 269-282. Somerville, MA: Cascadilla Proceedings Project.

Wittek, A. (2002). Learning the Meaning of Change-of-state Verbs: A Case Study of German Child Language. Berlin: Mouton de Gruyter.

Wright, W. L. D. (1996). A Grammar of the Arabic Language, Vol. 1. Beirut: Librairie du Liban.

Wunderlich, D. (2012). Operations on argument structure. In C. Maienborn, K. von Heusinger, \& P. Portner (Eds.), Semantics: An International Handbook of Natural Language Meaning, 3, 2224-2259. Berlin: Mouton de Gruyter.

\section{Notes}

Note 1. Before embarking on the study of these phenomena, it should be noted at this stage that SA (called in Arabic «Al FuSha» is distinguished from other spoken regional dialects in the Arabic world (known as Al Ya:mmija ). It is widely assumed that SA is nowadays the native language of no speakers anywhere in the world. In the present study, SA is assumed to be the language of written Arabic media, e.g., newspapers, books, journals, etc. - all forms of the printed word. It is also the language of public formal speaking and news broadcasts on radio and television. As far as the clause structure of this language is concerned, the unmarked word order is VSO. Morphologically, SA has a rich and diversified inflectional system (Number, Gender, Person, Case, Tense/Aspect are morphologically marked; i.e., there are specific affixes which encode these inflections).

The following abbreviations are used throughout this paper: $\mathrm{NOM}=$ Nominative. $\mathrm{ACC}=$ Accusative. $\mathrm{GEN} .=$ Genitive. OBL. = Oblique. $\mathrm{M}=$ Masculine. $\mathrm{F}=$ Feminine. $\mathrm{S}=$ Singular. $\mathrm{PL} .=$ Plural. PREF= Prefix. INF=Infix. REFL.$=$ Reflexive. Expl $=$ Expletive. ERG. $=$ Ergative. PART.$=$ Particle. PERF.$=$ Perfective. Unac $=$ Unaccusativizer. Moreover, the following symbols are used to refer to IPA symbols: $\mathrm{P}=$ Glottal stop. $\mathrm{C}=$ Voiced pharyngeal fricative. $\mathrm{V}=$ Voiced velar fricative. $\mathrm{z}=$ Voiced alveolar fricative. $\mathrm{x}=$ Voiceless velar fricative. $\breve{z}=$ Voiced postalveolar fricative. $\breve{s}=$ Voiced postalveolar fricative. $S=$ Voiceless retroflex fricative. $D=$ Voiced retroflex fricative. $\mathrm{T}=$ Retrofex plosive. In addition, morphemes are used between two slashes.

Note 2. By 'unaccusative change-of-state verbs,' I mean, in this study, verbs which denote the result state of the act of changing something into something different. On the other hand, change-of-state verbs are standardly defined as those verbs which denote the action of the bringing about of a result state.

Furthermore, I will specifically examine unaccusative verbs which denote an externally caused change of state; i.e., a change of state coming about because of something external to the entity that undergoes the change of state. For further details and an insightful discussion about the distinction between internally and externally caused change-of-state verbs with examples, see McKoon and Macfarland (2000:833-837) and Wittek (2002:5ff.).

Note 3. For further details about these operations and processes illustrated with examples, see Carnie, Sato, \& Siddiqi (2014: 338-341), Kiss and Alexiadou (2015:255-258), and Wunderlich (2012:2231-2245), among others.

Note 4. For more detail and insightful discussion with examples drawn from various languages, see Haspelmath and Sims (2010: 234-263). Payne (1997: 55) also points out that "[M]ost languages employ various derivational operations that adjust the argument structure of a verb."

Note 5. Haspelmath and Sims (2010: 240) define an 'antipassive' as "the term for a morphological operation whose effect is to background the patient in much the same way as the agent is backgrounded in the passive." 


\section{Copyrights}

Copyright for this article is retained by the author(s), with first publication rights granted to the journal.

This is an open-access article distributed under the terms and conditions of the Creative Commons Attribution license (http://creativecommons.org/licenses/by/4.0/). 